\title{
Article \\ Quality of Life Scores Remained Different among the Genotypic Groups of Patients with Suspected Hemochromatosis, Even after Treatment Period
}

\author{
Luis Alfredo Utria Acevedo ${ }^{1,+} \mathbb{D}$, Aline Morgan Alvarenga 1, ${ }^{+}$, Paula Fernanda Silva Fonseca ${ }^{2}$, \\ Nathália Kozikas da Silva ${ }^{1}$, Rodolfo Delfini Cançado ${ }^{3}$, Flavio Augusto Naoum ${ }^{4}$, Carla Luana Dinardo ${ }^{5}$, \\ Alexandre Costa Pereira ${ }^{2}$, Pierre Brissot ${ }^{6}$ and Paulo Caleb Junior Lima Santos ${ }^{1 \text {,* }}$
}

check for updates

Citation: Acevedo, L.A.U.; Alvarenga, A.M.; Fonseca, P.F.S.; da Silva, N.K.; Cançado, R.D.; Naoum, F.A.; Dinardo, C.L.; Pereira, A.C.; Brissot, P.; Santos, P.C.J.L. Quality of Life Scores Remained Different among the Genotypic Groups of Patients with Suspected Hemochromatosis, Even after Treatment Period. Genes 2022, 13, 118 . https://doi.org/10.3390/ genes13010118

Academic Editor: Mayka Sánchez Fernández

Received: 2 December 2021 Accepted: 22 December 2021 Published: 10 January 2022

Publisher's Note: MDPI stays neutral with regard to jurisdictional claims in published maps and institutional affiliations.

Copyright: (C) 2022 by the authors. Licensee MDPI, Basel, Switzerland. This article is an open access article distributed under the terms and conditions of the Creative Commons Attribution (CC BY) license (https:// creativecommons.org/licenses/by/ $4.0 /)$
1 Department of Pharmacology_Escola Paulista de Medicina, Universidade Federal de Sao Paulo (EPM-Unifesp), Sao Paulo 05403-904, Brazil; luisalfredoutria@hotmail.com (L.A.U.A.); a.cmorgan@hotmail.com (A.M.A.); nathalia.kozikas@unifesp.br (N.K.d.S.)

2 Laboratory of Genetics and Molecular Cardiology, Heart Institute (InCor), University of São Paulo Medical School, Sao Paulo 05403-904, Brazil; paulafonseca@usp.br (P.F.S.F.); acplbmpereira@gmail.com (A.C.P.)

3 Hematology and Hemotherapy Section, Santa Casa Medical School, Sao Paulo 05403-904, Brazil; rdcan@uol.com.br

4 Academia de Ciência e Tecnologia, Sao Jose do Rio Preto 15020-130, Brazil; fnaoum@hotmail.com

5 Fundação Pró-Sangue, Hemocentro de São Paulo, São Paulo, Brazil, Universidade de São Paulo (USP), Sao Paulo 05403-904, Brazil; caludinardo@gmail.com

6 Institut NuMeCan, Inserm U-1241, Univ Rennes 1, 35000 Rennes, France; pierre.brissot@gmail.com

* Correspondence: paulo.caleb@unifesp.br

+ These authors contributed equally to this work.

\begin{abstract}
AbstractBackground: Hemochromatosis is a genetic condition of iron overload caused by deficiency of hepcidin. In a previous stage of this study, patients with suspected hemochromatosis had their quality of life (QL) measured. We observed that QL scores differed among genotypic groups of patients. In this reported final phase of the study, the aims were to compare QL scores after a treatment period of approximately 3 years and to analyze a possible association of the serum ferritin values with QL scores. Methods: Sixty-five patients were enrolled in this final phase and divided into group 1 (patients that showed primary iron overload and homozygous genotype for the HFE p.Cys282Tyr mutation) and group 2 (other kinds of genotypes). Short Form 36 (SF-36) was performed and consisted of eight domains with a physical and also a mental component. Results: Both groups had a significant decrease in serum ferritin concentrations: group 1 had a variation from $1844 \pm 1313 \mathrm{ng} / \mathrm{mL}$ to $281 \pm 294 \mathrm{ng} / \mathrm{mL}$, and group 2 had a variation from $1216 \pm 631 \mathrm{ng} / \mathrm{mL}$ to $236 \pm 174 \mathrm{ng} / \mathrm{mL}$. Group 1 had a smaller mean value for these six SF-36 domains compared with group 2, indicating a worse QL. Conclusions: In this final stage, six domains demonstrated a difference among genotypic groups (role emotional and mental health, adding to the four of the initial phase), reassuring the impact of the identified genotype on the QL of hemochromatosis patients. Furthermore, despite that both patient groups demonstrated similar and significant decreases in serum ferritin values, no association was found between the decrease in this biological parameter and the SF-36 domains.
\end{abstract}

Keywords: hemochromatosis; short form health survey; quality of life; SF-36; phlebotomy; iron overload

\section{Introduction}

Hemochromatosis is a genetic condition of iron overload caused by deficiency of hepcidin, making the absorption of dietary iron exceed the requirements. Hemochromatosis excludes the acquired iron overload [1,2], and it is caused by mutations in the five main genes; however, it is more frequently associated with the p.Cys282Tyr (C282Y) homozygous genotype, which is the most common genetic alteration associated with hemochromatosis, 
in the HFE gene [1,3]. The diagnosis is based on laboratory tests (transferrin saturation and serum ferritin) [4], genetic tests, and/or magnetic resonance imaging (which helps with the quantification of iron). Regarding treatment, phlebotomy is the safest and cheapest option to remove iron excess in the body in order to reduce mortality and comorbidities [1,3,5-8].

The World Health Organization (WHO) defines quality of life (QL) as "the individuals" perception of their position in life in the context of the culture and value systems in which they live and in relation to their goals, expectations, standards and concerns" $[9,10]$. The Short Form 36 (SF-36) questionnaire is a popular generic instrument to evaluate healthrelated quality of life [11]. It consists of eight domains comprising physical and mental component scores, and it has been validated for the Brazilian population in the Portuguese language $[12,13]$.

In this scenario, the main aims of the reported final phase of this study were to compare QL scores according to genotypic groups of patients after a treatment period of approximately 3 years and to further evaluate a possible association of the serum ferritin values with QL scores.

\section{Methods}

\subsection{Patients}

In an initial phase of the study by our group, evaluating the QL of 79 patients with suspected hemochromatosis, we observed that four of the eight domains of the SF-36 questionnaire were significantly different among genotypic groups of patients. Group 1 (patients with primary iron overload and that demonstrated homozygous genotype for the HFE p.Cys282Tyr) had worse QL scores compared with group 2 (the one that had the patients with primary iron overload and other genotypes) [13]. In this scenario, the main aims of the reported final phase of this study were to compare QL scores according to the genotypic groups of patients after a treatment period of approximately 3 years and to further analyze a possible association of the serum ferritin values with QL scores.

The study protocol was approved by the research ethics committee of the Universidade Federal de São Paulo CEP/Unifesp (1195/2018), and consent forms of the patients were obtained prior to entering the study. Patients were selected from hematologic clinics (Ambulatório do Hemocentro da Santa Casa-São Paulo, Ambulatório de Hematologia do Hospital das Clínicas-São Paulo, and Instituto Naoum de Hematologia—São José do Rio Preto, Brazil). The inclusion criteria were: age older than or equal to 18 years, transferrin saturation (TS) greater than or equal to $45 \%$, and serum ferritin (SF) $\geq 300 \mathrm{ng} / \mathrm{mL}$ for males or $\geq 200 \mathrm{ng} / \mathrm{mL}$ for females. Otherwise, the exclusion criteria were: patients with positive serology for hepatitis (B or C), alcoholic liver disease, high alcoholic consumption (more than $20 \mathrm{~g}$ daily), hemolytic anemias, repeated blood transfusions, metabolic syndrome, or insulin resistance not resulting from hemochromatosis. In this study, we also excluded patients with juvenile hemochromatosis carrying HAMP and HJV mutations $[14,15]$.

The first phase of this study was described by Fonseca et al. [13]. In this phase, 79 patients were analyzed, in which they proposed to verify whether QL domains, assessed by SF-36, were different or not according to genotypic groups in the patients with suspected hemochromatosis. Two meetings were held with these patients in this step. Between these procedures, the patients were followed up by their doctors of origin. After this analysis, the patients received a report and guidance on their results. The second part of this study aimed to compare the QL scores after a treatment period of approximately 3 years in order to assess a possible association of serum ferritin values with QL scores. It is important to consider that we had a change in the total number of patients. Thirteen patients were lost to follow-up, and one patient died. Considering this, we were able to enroll 65 patients (after the initial treatment period of approximately 3 years). In this second phase of the study, calls were made, e-mails were sent, and letters and remote conversations were obtained to gather information. During these 3 years, the patients were followed up by their doctors of origin, and they were randomly included. Patients who were able to participate in the 
study generally accepted. We do not have data on patients who agreed to participate and those who declined. All who agreed to participate signed the informed consent form.

\subsection{SF-36 Health Survey}

The SF-36 questionnaire consists of 36 questions and measures eight domains: physical functioning, role physical, bodily pain, general health, vitality, social functioning, role emotional, and mental health. All participants in groups 1 and 2 answered the SF-36 questionnaire applied by an interviewer, or it was self-administered and reviewed by an interviewer. Each of the 36 questions has a fixed value. After, these values were converted to raw scale, which provided the score of each domain. The values range from 0 to 100 points, where higher scores indicate a better health condition [11,16-18].

\subsection{Statistical Analysis}

Categorical variables are represented as percentages, while continuous variables are represented as means \pm standard deviations. Kolmogorov-Smirnov test was used to test normality. Chi-squared or Fisher tests were performed to compare the categorical variables (such as gender, self-declared race/color, education level, and consumption of alcohol) according to the genotypic group. Student's $t$-test was used to compare the values of the SF-36 domains and serum ferritin between groups 1 and 2. The values of the SF-36 domains and serum ferritin were adjusted for age and gender. SF-36 domains and serum ferritin values also had paired analyses (paired-samples Student's $t$-test) comparing initial and final phases. Pearson correlation test was performed for the variables' initial and final serum ferritin values and SF-36 domains. The level of significance was defined at $p \leq 0.05$. All statistical analyses were carried out using the SPSS software (Version 20.0).

\section{Results}

Sixty-five of 79 patients were enrolled in this final phase of the present study. Two genotypic groups were formed: group 1 consisted of patients with primary iron overload and homozygous genotype for the HFE p.Cys282Tyr mutation $(n=23)$, and group 2 consisted of patients with primary iron overload and other genotypes (compound heterozygosity for the p.Cys282Tyr/p.His63Asp mutation $(n=10)$, heterozygosity for the p.Cys282Tyr $(n=4)$, homozygosity $(n=10)$, heterozygosity $(n=8)$ for the p.His63Asp, or absence of p.Cys282Tyr or p.His63Asp $(n=10))$. There was a loss of treatment follow-up for six and eight patients from groups 1 and 2, respectively.

Table 1 shows the general characteristics related to genotypic groups of the patients. Group 1 had a lower percentage of males $(34.8 \%)$ and similar mean serum ferritin values $(281 \pm 294 \mathrm{ng} / \mathrm{mL})$ compared with group $2(85.7 \%, 236 \pm 174 \mathrm{ng} / \mathrm{mL} ; p=0.001, p=0.53$, respectively).

Figure 1 shows comparisons of mean serum ferritin values of groups 1 and 2 according to the initial and final phases. Group 1 had mean serum ferritin values of $1844 \pm 1313 \mathrm{ng} / \mathrm{mL}$ in the initial phase and $281 \pm 294 \mathrm{ng} / \mathrm{mL}$ in the final phase $(p<0.001)$. Group 2 had mean serum ferritin levels of $1216 \pm 631 \mathrm{ng} / \mathrm{mL}$ in the initial phase and $243 \pm 184 \mathrm{ng} / \mathrm{mL}$ in the final phase $(p<0.001)$. In addition, Figure 1 shows no significant differences for mean serum ferritin values between groups 1 and 2 in the final phase $(p=0.53)$. Additional file 2: Table S2 shows that there was no correlation between serum ferritin (initial and final) values and SF-36 domains, except a weak correlation between physical functions and serum ferritin in the final phase $(\mathrm{r}=-0.352, p=0.008)$.

Table 2 shows the average values of the SF- 36 domains related to patient groups. Six domains were significantly different between groups 1 and 2: bodily pain $(p=0.03)$, general health perception $(p=0.03)$, vitality $(p=0.01)$, social functioning $(p=0.01)$, role emotional $(p=0.001)$ and mental health $(p=0.04)$. Group 1 demonstrated lower average values for these six domains when compared with group 2. In addition, patients with HFE p.Cys282Tyr homozygous genotype, who had four SF-36 domains worse in the initial phase of this study, remained worse, and further, had two worsening domains (role emotional and 
mental health) in this final phase. This finding was observed even with the average treatment duration of 3 years and despite a similar decrease in ferritin values to that of group 2, reaffirming the impact of the identified genotype on the QL of hemochromatosis patients.

Table 1. General characteristics of follow-up according to patient genotypic groups.

\begin{tabular}{|c|c|c|c|}
\hline & $\begin{array}{c}\text { Group } 1^{\mathrm{a}} \\
n=23\end{array}$ & $\begin{array}{c}\text { Group } 2^{b} \\
n=42\end{array}$ & $p$-Value \\
\hline Gender (male), \% & 34.8 & 85.7 & 0.001 \\
\hline Age (years), mean \pm SD & $50 \pm 13$ & $54 \pm 12$ & 0.21 \\
\hline Serum ferritin $(\mathrm{ng} / \mathrm{mL})$, mean $\pm \mathrm{SD}$ & $281 \pm 294$ & $236 \pm 174$ & 0.53 \\
\hline Number of phlebotomies & $8.8 \pm 6.3$ & $5.3 \pm 5.8$ & 0.72 \\
\hline \multicolumn{4}{|l|}{ Self-declared race/color, $\%$} \\
\hline White & 78.3 & 92.9 & \multirow{3}{*}{0.15} \\
\hline Intermediate & 17.4 & 4.8 & \\
\hline Asian and Amerindian & 4.3 & 2.3 & \\
\hline \multicolumn{4}{|l|}{ Level of education, \% } \\
\hline University & 65.2 & 73.8 & \multirow{2}{*}{0.89} \\
\hline Others & 34.8 & 26.2 & \\
\hline \multicolumn{4}{|l|}{ Consumption of alcoholic beverages, $\%$} \\
\hline Never & 52.2 & 31.0 & \multirow{3}{*}{0.20} \\
\hline Occasionally & 43.5 & 57.1 & \\
\hline Frequently & 4.3 & 11.9 & \\
\hline
\end{tabular}

a Group 1: 23 patients with primary iron overload and homozygosity for the p.Cys282Tyr mutation. b Group 2: 42 patients with primary iron overload and other genotypes: compound heterozygosity for the p.Cys282Tyr/p.His63Asp $(n=10)$, heterozygosity for the p.Cys282Tyr $(n=4)$, homozygosity $(n=10)$ or heterozygosity $(n=8)$ for the p.His63Asp, or absence of p.Cys282Tyr and p.His63Asp $(n=10)$.

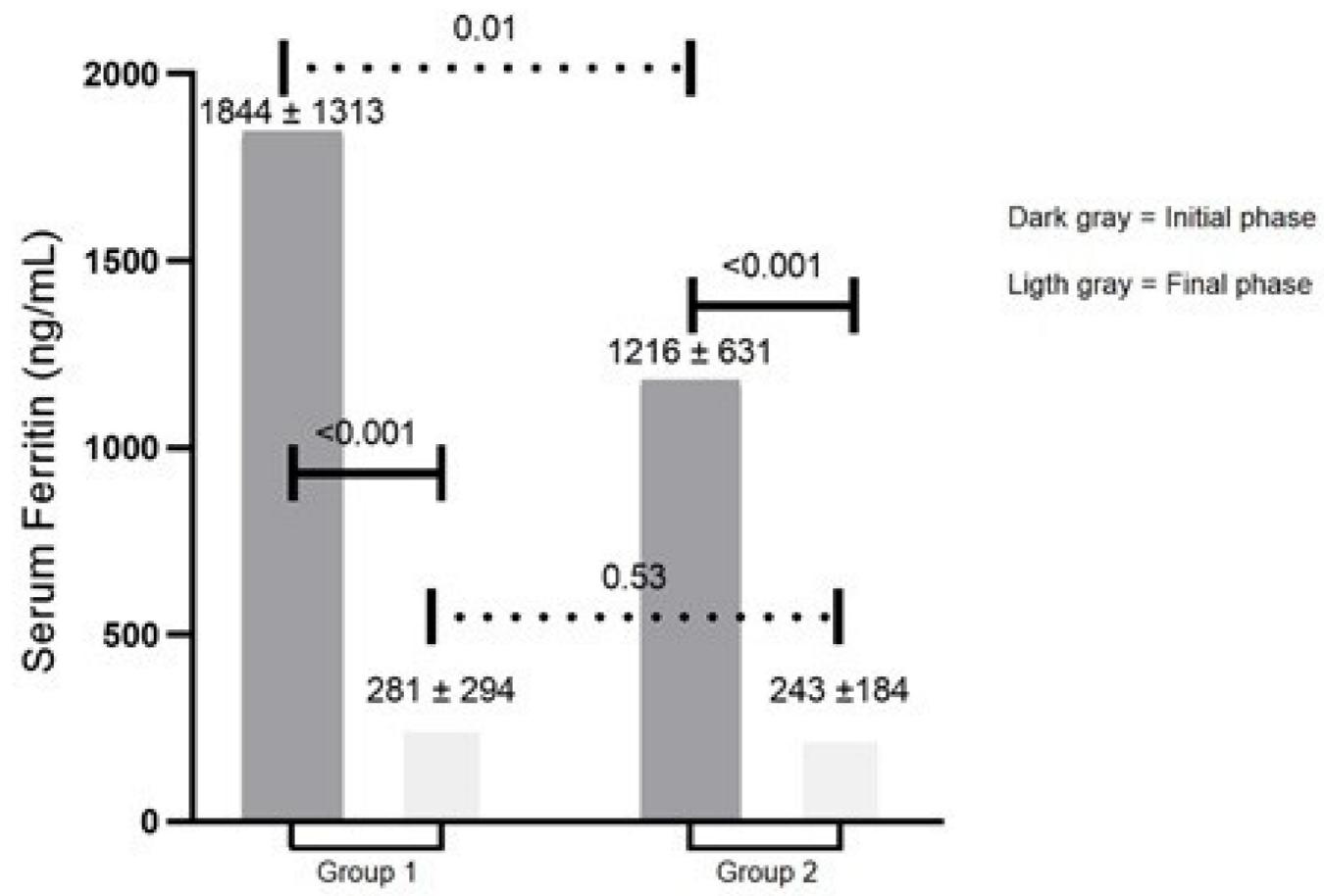

Figure 1. Comparisons of serum ferritin means of groups 1 and 2 in the initial and final phases. Group 1: 23 patients with primary iron overload and homozygosity for the p.Cys282Tyr mutation. Group 2: 42 patients with primary iron overload and other genotypes: compound heterozygosity for the p.Cys282Tyr/p.His63Asp $(n=10)$, heterozygosity for the p.Cys282Tyr $(n=4)$, homozygosity $(n=10)$ or heterozygosity $(n=8)$ for the p.His63Asp, or absence of p.Cys282Tyr and p.His63Asp $(n=10)$. 
Table 2. Mean ( \pm standard deviation) values of the SF-36 domains according to genotypic groups of the patients.

\begin{tabular}{cccc}
\hline SF-36 Domains Group 1a & $\begin{array}{c}\text { Group 1 } \\
\boldsymbol{n}=\mathbf{2 3}\end{array}$ & $\begin{array}{c}\text { Group 2 } \\
\boldsymbol{n}=\mathbf{4 2}\end{array}$ & $\boldsymbol{p}$-Value \\
\hline Physical functions & $84 \pm 24$ & $82 \pm 22$ & 0.34 \\
Role physical & $74 \pm 43$ & $73 \pm 36$ & 0.13 \\
Bodily pain & $64 \pm 30$ & $74 \pm 24$ & 0.03 \\
General health perception & $58 \pm 21$ & $69 \pm 21$ & 0.03 \\
Vitality & $56 \pm 24$ & $67 \pm 21$ & 0.01 \\
Social functioning & $68 \pm 31$ & $87 \pm 22$ & 0.01 \\
Role emotional & $57 \pm 45$ & $83 \pm 30$ & 0.01 \\
Mental health & $69 \pm 22$ & $77 \pm 20$ & 0.04 \\
\hline
\end{tabular}

a Group 1: 23 patients with primary iron overload and homozygosity for the p.Cys282Tyr mutation. ${ }^{b}$ Group 2: 42 patients with primary iron overload and other genotypes: compound heterozygosity for the p.Cys282Tyr /p.His63Asp $(n=10)$, heterozygosity for the p.Cys282Tyr $(n=4)$, homozygosity $(n=10)$ or heterozygosity $(n=8)$ for the p.His63Asp, or absence of p.Cys282Tyr and p.His63Asp $(n=10)$.

\section{Discussion}

Some studies reported interesting data on QL in patients with hemochromatosis; however, to the best of our knowledge, the present study is the first to evaluate SF-36 over different periods of treatment. Graaff et al. conducted a study using the Assessment of Quality of Life 4D instrument (AQOL-4D) in 270 patients with a hemochromatosis diagnosis in Australia, assessing the usefulness of the population's health status. The range of the tool was from -0.04 to 1.00 , where a score of 1 represents optimal health, a score of 0 represents a state equivalent to death, and a score below 0 represents a state worse than death. The average usefulness for the general population was 0.81 , and that of patients with hemochromatosis was 0.66 . The symptomatic states of hemochromatosis presented less utility with respect to the asymptomatic states of the disease [19]. Some studies did not identify significant differences in the QL between hemochromatosis patients and subjects without iron overload. Shaheen et al. conducted a study in the United States with 126 hemochromatosis patients with HFE homozygosity for the p.Cys282Tyr or compound heterozygosity for the p.Cys282Tyr/p.His63Asp mutation subjects, but who had evidence of final organ injury or symptoms attributable to iron overload and compared them with their unaffected siblings with the illness. The QL measured by the SF-36 questionnaire between the subjects with hemochromatosis and the unaffected siblings or the population means were not significantly different [20]. Meiser et al. also compared in Australia the QL of 30 patients clinically affected with hemochromatosis and 66 unaffected subjects despite carrying the homozygous genotype of hemochromatosis and did not find any differences between the two groups for both the mental and physical components of the QL questionnaire.

In the present study, there was a greater number of male patients in group 2 when compared with group 1, as shown in Table 1, so much so that there was a significant difference between the groups shown by the $p$-value of 0.001 .

It may be related to women's well-known body protection due to menstruations and pregnancies and, in addition, to the very low penetrance of genotypes from group $2[5,21]$. We observed the worsening of the emotional role domain in group 1, which may have been influenced by the knowledge of a positive result for a genetic test plus the influence of treatment by phlebotomies [22-26]. Rombout et al. reported that $52 \%$ of 46 patients during the induction phase of treatment and $37 \%$ in the maintenance phase had negative experiences related to treatment, and $16 \%$ of patients would even decide not to continue with phlebotomies where alternative options are available [21,26]. Meiser et al. also reported that some patients treated with phlebotomy for a year suffered a decrease in the values of emotional and mental components at this time [20]. Brissot et al. also reported the incidence of the frequency of phlebotomies in the daily life of patients who received phlebotomies once a week; $26 \%(n=23 / 90)$ expressed feeling uncomfortable or very 
uncomfortable with previous procedures, during and after the bleeding. Many of them expressed a definite desire to stop phlebotomy if there was another treatment available due to all the discomfort that this procedure represented for them [27]. Here, it is important to highlight the necessity to observe the emotional and mental aspects of hemochromatosis patients and to explain that treatment is the best option for their health and QL.

Comparing the initial and final ferritin values of the studied groups, although the values decreased significantly, we observed that they did not reach the proposed objectives by the current international recommendations for the treatment of hemochromatosis, namely reaching and maintaining serum ferritin levels around $50 \mathrm{ng} / \mathrm{mL}$ [8]. American and European guidelines also recommend serum ferritin values at $50-100 \mathrm{ng} / \mathrm{mL}$ in the maintenance phase [28-30]. Thus, we were not able to identify a possible relationship between QL and values of serum ferritin $\sim 50 \mathrm{ng} / \mathrm{mL}$.

The differences in the domains' values between the two genotypic groups can be explained, at least in part, by the genetic basis of the disease and its respective mutations, iron status, and phlebotomies, even we were not able to identify a significant association with some of these variables in the present study. The EMQN guide detailed the respective associations between genotypes and clinical penetrance with respect to possible ferritin and transferrin saturation values in patients [31]: p.Cys is compatible with hemochromatosis related to HFE in the presence of evidence of iron overload; patients with compound p.Cys282Tyr/p.His63Asp may be in danger of developing mild to moderate iron overload in association with comorbidity factors (metabolic syndrome or chronic alcoholism); otherwise, carriers of the p.Cys282Tyr changes in heterozygosis, homozygosis for p.His63Asp, and heterozygosis for $\mathrm{p}$.His63Asp have no greater risk of developing hemochromatosis related to HFE.

The worsening in quality of life, even with treatment, can be associated with other pre-existing diseases. According to the therapeutic recommendation for hemochromatosis, the ideal would be to maintain treatment and follow-up because, without this followup, the quality of life could worsen. Recent studies observed a beneficial effect of early and sustained management of patients with iron excess, even when iron load is mild or moderately elevated serum ferritin [8].

\section{Strengths and Limitations}

Our study has some limitations. First, we did not perform a correction for multiple testing. However, the statistical comparison performed was able to capture many SF-36 domains differently with the inclusion criteria for the genotypic groups; furthermore, we identified a numerical difference among groups, which supports these findings (especially in Table 2). Second, liver magnetic resonance imaging was not available in the initial and final phases. Third, during the treatment period, we did not have exact data on some items that could have influenced serum ferritin values, such as inflammatory and/or metabolic conditions/diseases, liver injuries, and/or alcohol consumption. However, it is argued that the initial inclusion criteria were stringent, including transferrin saturation $\geq 45 \%$ and serum ferritin $\geq 300 \mathrm{ng} / \mathrm{mL}$ for males or $\geq 200 \mathrm{ng} / \mathrm{mL}$ for females. Further, strict exclusion criteria were enforced for patients with positive serology for hepatitis, alcoholic liver disease, alcohol consumption (more than $20 \mathrm{~g} /$ day), hemolytic anemias, repeated blood transfusions, metabolic syndrome, or insulin resistance not resulting from hemochromatosis. Fourth, the number of phlebotomies was not available for all patients in a network system.

\section{Conclusions}

In this final phase, six SF-36 domains were different between genotypic groups (role emotional and mental health, in addition to the four of the initial phase), reaffirming the impact of identified genotype on the QL of hemochromatosis patients. Furthermore, despite a similar ferritin decrease between both patient groups, no differences were observed for the SF-36 domains. 
Supplementary Materials: The following are available online at https:/ /www.mdpi.com/article/10 .3390 / genes13010118/s1, Table S1: Comparison of mean ( \pm standard deviation) values of the SF-36 domains according with initial and final phases among patient groups; Table S2: Comparison of serum ferritin $(\mathrm{ng} / \mathrm{mL})$ values and the SF-36 domains according with initial and final phases in overall patient group.

Author Contributions: L.A.U.A., A.M.A. and P.C.J.L.S. drafted the study protocol. L.A.U.A. and A.M.A. are two co-authors that participated in the original manuscript writing. P.F.S.F., R.D.C., F.A.N., C.L.D., A.C.P., P.B. and P.C.J.L.S. participated in the design of the study. P.F.S.F., R.D.C., F.A.N. and C.L.D. selected and followed the patients. P.F.S.F. carried out the genetic tests. P.C.J.L.S. performed the statistical analysis and coordinated the study. N.K.d.S. participated in the writing and submission of the manuscript. All authors have read and agreed to the published version of the manuscript.

Funding: L.A.U.A is a recipient of fellowships from Coordenação de Aperfeiçoamento de Pessoal de Nível Superior (CAPES). Coordenação de Aperfeiçoamento de Pessoal de Nível Superior (CAPES) 001 and Fundação de Amparo à Pesquisa do Estado de São Paulo (FAPESP) process number: 2019/08338-7.

Institutional Review Board Statement: The studies involving human participants were reviewed and approved by Ethics committee of the Universidade Federal de São Paulo CEP/Unifesp (1195/2018). The patients/participants provided their written informed consent to participate in this study.

Informed Consent Statement: Not applicable. All patients signed a consent term.

Data Availability Statement: We do not wish to share our data because more clinical variables will be studied.

Acknowledgments: We thank the patients and health and technical professionals who participated in the study.

Conflicts of Interest: The authors declare no conflict of interest.

\section{Abbreviations}

WHO, World Health Organization; QL, quality of life; SF-36, Short Form 36 questionnaire Implications for policy, practice and research.

\section{References}

1. Brissot, P.; Pietrangelo, A.; Adams, P.C.; Graaff, B.; De McLaren, C.E.; Loreál, O. Haemochromatosis. Nat. Rev. Dis. Prim. 2018, 4, 1-15. [CrossRef] [PubMed]

2. Radford-Smith, D.E.; Powell, E.E.; Powell, L.W. Haemochromatosis: A clinical update for the practising physician. Intern. Med. J. 2018, 48, 509-516. [CrossRef] [PubMed]

3. Brissot, P.; Troadec, M.-B.; Loréal, O.; Brissot, E. Pathophysiology and classification of iron overload diseases; update 2018. Transfus. Clin. Biol. 2019, 26, 80-88. [CrossRef] [PubMed]

4. Santos, P.C.J.L.; Krieger, J.E.; Pereira, A.C. Molecular Diagnostic and Pathogenesis of Hereditary Hemochromatosis. Int. J. Mol. Sci. 2012, 13, 1497-1511. [CrossRef]

5. Pilling, L.C.; Tamosauskaite, J.; Jones, G.; Wood, A.R.; Jones, L.; Kuo, C.L.; Kuchel, G.A.; Ferrucci, L.; Melzer, D. Common conditions associated with hereditary haemochromatosis genetic variants: Cohort study in UK Biobank. BMJ 2019, $364,5222$. [CrossRef]

6. Brissot, P.; Loréal, O. Iron metabolism and related genetic diseases: A cleared land, keeping mysteries. J. Hepatol. 2016, 64, 505-515. [CrossRef]

7. Pietrangelo, A. Non-HFE hemochromatosis. Semin. Liver Dis. 2005, 25, 450-460. [CrossRef]

8. Adams, P.; Altes, A.; Brissot, P.; Butzeck, B.; Cabantchik, I.; Cançado, R.; Distante, S.; Evans, P.; Evans, R.; Ganz, T.; et al. Therapeutic recommendations in HFE hemochromatosis for p.Cys282Tyr (C282Y/C282Y) homozygous genotype. Hepatol. Int. 2018, 12, 83-86. [CrossRef]

9. WHO. The World Health Organization quality of life assessment (WHOQOL): Position paper from the World Health Organization. Soc. Sci. Med. 1995, 41, 1403-1409. [CrossRef]

10. Rogerson, R.J. Environmental and health-related quality of life: Conceptual and methodological similarities. Soc. Sci. Med. 1995, 41, 1373-1382. [CrossRef]

11. Lins, L.; Carvalho, F.M. SF-36 total score as a single measure of health-related quality of life: Scoping review. SAGE Open Med. 2016, 4, 205031211667172. [CrossRef] 
12. Ciconelli, R.M.; Ferraz, M.B.; Santos, W.; Meinão, I.; Quaresma, M.R. Tradução para a língua portuguesa e validação do questionário genérico de avaliação de qualidade de vida SF-36 (Brasil SF-36). Rev. Bras Reum. 1999, 39, $143-150$.

13. Fonseca, P.F.; Cançado, R.D.; Naoum, F.A.; Dinardo, C.L.; Fonseca, G.H.; Gualandro, S.F.; Krieger, J.E.; Pereira, A.C.; Brissot, P.; Santos, P.C. Quality of life scores differs between genotypic groups of patients with suspected hereditary hemochromatosis. BMC Med. Genet. 2018, 19, 3. [CrossRef]

14. Fonseca, P.F.S.; Cançado, R.D.; Uellendahl Lopes, M.M.; Correia, E.; Lescano, M.A.; Santos, P.C.J.L. HAMP Gene Mutation Associated with Juvenile Hemochromatosis in Brazilian Patients. Acta Haematol. 2016, 135, 228-231. [CrossRef]

15. De Lima Santos, P.C.; Pereira, A.C.; Cançado, R.D.; Schettert, I.T.; Hirata, R.D.; Hirata, M.H.; Figueiredo, M.S.; Chiattone, C.S.; Krieger, J.E.; Guerra-Shinohara, E.M. Hemojuvelin and Hepcidin Genes Sequencing in Brazilian Patients with Primary Iron Overload. Genet. Test. Mol. Biomark. 2010, 14, 803-806. [CrossRef]

16. Martinez-Martin, P. What is quality of life and how do we measure it? Relevance to Parkinson's disease and movement disorders. Mov. Disord. 2017, 32, 382-392. [CrossRef]

17. Pan, Y.; Barnhart, H.X. Methods for assessing the reliability of quality of life based on SF-36. Stat. Med. 2016, 35, 5656-5665. [CrossRef]

18. Ware, J.E.; Snow, K.K.; Kosinski, M.; Gandek, B. SF-36 Health Survey: Manual and Interpretation Guide; Health Institute, New England Medical Center: Boston, MA, USA, 1993.

19. De Graaff, B.; Neil, A.; Sanderson, K.; Yee, K.C.; Palmer, A.J. Quality of life utility values for hereditary haemochromatosis in Australia. Health Qual. Life Outcomes 2016, 14, 31. [CrossRef]

20. Van der Plas, S.M.; Hansen, B.E.; de Boer, J.B.; Stijnen, T.; Passchier, J.; Rob, A.; Schalm, S.W. Generic and disease-specific health related quality of life of liver patients with various aetiologies: A survey. Qual. Life Res. 2007, 16, 375-388. [CrossRef]

21. Shaheen, N.J.; Lawrence, L.B.; Bacon, B.R.; Barton, J.C.; Barton, N.H.; Galanko, J.; Martin, C.F.; Burnett, C.K.; Sandler, R.S. Insurance, employment, and psychosocial consequences of a diagnosis of hereditary hemochromatosis in subjects without end organ damage. Am. J. Gastroenterol. 2003, 98, 1175-1180. [CrossRef]

22. Meiser, B.; Dunn, S.; Dixon, J.; Powell, L.W. Psychological Adjustment and Knowledge about Hereditary Hemochromatosis in a Clinic-Based Sample: A Prospective Study. J. Genet. Couns. 2005, 14, 453-463. [CrossRef]

23. Rombout-Sestrienkova, E.; Winkens, B.; Essers, B.A.; Nieman, F.H.; Noord, P.A.; Janssen, M.C.; van Deursen, C.T.; Boonen, A.; Reuser-Kaasenbrood, E.P.; Heeremans, J.; et al. Erythrocytapheresis versus phlebotomy in the maintenance treatment of HFE hemochromatosis patients: Results from a randomized crossover trial. Transfusion 2016, 56, 261-270. [CrossRef]

24. Ong, S.Y.; Gurrin, L.C.; Dolling, L.; Dixon, J.; Nicoll, A.J.; Wolthuizen, M.; Wood, E.M.; Anderson, G.J.; Ramm, G.A.; Allen, K.J.; et al. Reduction of body iron in HFE-related haemochromatosis and moderate iron overload (Mi-Iron): A multicentre, participant-blinded, randomised controlled trial. Lancet Haematol. 2017, 4, e607-e614. [CrossRef]

25. Milet, J.; Déhais, V.; Bourgain, C.; Jouanolle, A.M.; Mosser, A.; Perrin, M.; Morcet, J.; Brissot, P.; David, V.; Deugnier, Y.; et al Common variants in the BMP2, BMP4, and HJV genes of the hepcidin regulation pathway modulate HFE hemochromatosis penetrance. Am. J. Hum. Genet. 2007, 81, 799-807. [CrossRef]

26. Rombout-Sestrienkova, E.; Koek, G.H.; Neslo, R.; van Kraaij, M.; Menheere, P.P.; Masclee, A.; Swinkels, D.W. Course of iron parameters in HFE-hemochromatosis patients during initial treatment with erythrocytapheresis compared to phlebotomy. J. Clin. Apher. 2016, 31, 564-570. [CrossRef]

27. Brissot, P.; Ball, S.; Rofail, D.; Cannon, H.; Jin, V.W. Hereditary hemochromatosis: Patient experiences of the disease and phlebotomy treatment. Transfusion 2011, 51, 1331-1338. [CrossRef]

28. Bacon, B.R.; Adams, P.C.; Kowdley, K.V.; Powell, L.W.; Tavill, A.S. Diagnosis and management of hemochromatosis: 2011 Practice Guideline by the American Association for the Study of Liver Diseases. Hepatology 2011, 54, 328-343. [CrossRef]

29. Kowdley, K.V.; Brown, K.E.; Ahn, J.; Sundaram, V. ACG Clinical Guideline. Am. J. Gastroenterol. 2019, 114, 1202-1218. [CrossRef]

30. European Association for the Study of the Liver. EASL clinical practice guidelines for HFE hemochromatosis. J. Hepatol. 2010, 53, 3-22. [CrossRef]

31. Porto, G.; Brissot, P.; Swinkels, D.W.; Zoller, H.; Kamarainen, O.; Patton, S.; Alonso, I.; Morris, M.; Keeney, S. EMQN best practice guidelines for the molecular genetic diagnosis of hereditary hemochromatosis (HH). Eur. J. Hum. Genet. 2016, 24, 479-495. [CrossRef] 